\title{
Assessing Rate-Reducing Foliar Resistance to Anthracnose Crown Rot and Fruit Rot in Strawberry
}

\author{
Raymond L. Jacobs, ${ }^{1}$ Tika B. Adhikari, ${ }^{2, \dagger}$ Jeremy Pattison, ${ }^{1}$ G. Craig Yencho, ${ }^{1}$ Gina E. Fernandez, ${ }^{1}$ and Frank J. Louws ${ }^{1,2, \dagger}$ \\ ${ }^{1}$ Department of Horticultural Science, North Carolina State University, Raleigh, NC 27695 \\ ${ }^{2}$ Department of Entomology and Plant Pathology, North Carolina State University, Raleigh, NC 27695
}

\begin{abstract}
Anthracnose fruit rot and anthracnose crown rot (ACR) caused by two species complexes of the fungus referred to as Colletotrichum acutatum and Colletotrichum gloeosporioides, respectively, are major pathogens of strawberry in North Carolina. Anthracnose epidemics are common when susceptible cultivars and asymptomatic planting stocks carrying quiescent Colletotrichum infection or hemibiotrophic infection (HBI) are planted. The main objective of this study was to assess resistance to HBI and ACR in strawberry. Strawberry cultivars and breeding lines were spray inoculated with isolates of $C$. acutatum or $C$. gloeosporioides. Four epidemiological parameters providing estimates of rate-reducing resistance to HBI and ACR in strawberry cultivars and lines were eval-

ACR severity was rated weekly for wilt symptoms, and relative area under disease progress curve scores were calculated for comparing strawberry cultivars and lines. Significant differences $(P \leq 0.005)$ in HBI severity were found among strawberry genotypes; however, the correlations were not remarkable between Colletotrichum species $(r=$ $0.4251)$. Although significant variation in resistance was observed for ACR, this was also weakly correlated $(r=0.2430)$ with resistance to $C$. gloeosporioides HBI. Overall, rate-reducing resistance to $\mathrm{HBI}$ and ACR in strawberry identified in this study could be utilized in breeding programs to develop durable resistance to anthracnose in North Carolina.
\end{abstract} uated in repeated experiments in controlled environments in a greenhouse. HBI severity, measured as the percentage of total leaf area covered by acervuli, was estimated visually and by image analysis.
Keywords: etiology, fungi, fruit, pathogen detection, small fruits, techniques
The cultivated strawberry (Fragaria $\times$ ananassa Duchesne) is a major fruit crop in North Carolina (NC) and the southeastern United States (Louws and Rahman 2012). Anthracnose fruit rot (AFR) and anthracnose crown rot (ACR) caused by Colletotrichum acutatum sensu lato (s. l.) and Colletotrichum gloeosporioides sensu lato (s. l.), respectively, are the most devastating diseases of strawberry (Legard 2000; Poling 2008) in NC. Based on the multilocus sequence analysis (MLSA), isolates of C. acutatum s. l. and C. gloeosporioides s. $l$. are considered as $C$. acutatum species complex and C. gloeosporioides species complex, respectively (Boroncelli et al. 2015; Damm et al. 2012; Weir et al. 2012). In 2015, 148 isolates of the United Kingdom and global diversity of $C$. acutatum s. $l$. populations have been analyzed using four sequence loci: glyceraldehyde-3-phosphate dehydrogenase (GAPDH), ribosomal internal transcribed spacer (ITS), mating-type gene (MAT1-2), and $\beta$-tubulin 2 (TUB) (Boroncelli et al. 2015). Furthermore, these $C$. acutatum $s$. $l$. isolates were designated into three species (Colletotrichum nymphaeae, Colletotrichum godetiae, and Colletotrichum fioriniae) (Boroncelli et al. 2015) after a 2012 taxonomic reclassification (Damm et al. 2012). To be consistent with past literature, we will refer to the

Current address of R. L. Jacobs: Driscoll's, Inc., Dover, FL 33527. Current address of J. Pattison: Driscoll's, Inc., Watsonville, CA 95076.

${ }^{\dagger}$ Corresponding authors: T. B. Adhikari; tbadhika@ncsu.edu, and F. J. Louws; frank_louws@ncsu.edu

Funding: This study was partially supported by the North Carolina Strawberry Association, the North American Strawberry Grower Association, and the Southern Region Small Fruit Consortium.

*The $\boldsymbol{e}$-Xtra logo stands for "electronic extra" and indicates that two supplementary figures are published online.

The author(s) declare no conflict of interest.

Accepted for publication 27 August 2019

() 2020 The American Phytopathological Society anthracnose pathogens of strawberry herein as $C$. acutatum and $C$. gloeosporioides.

The symptoms of ACR are characterized by the presence of reddish brown marbled necrosis of crown tissue, resulting in wilt and eventual plant collapse (Rahman et al. 2015). AFR produces dark sunken lesions on developing fruits that render them unmarketable (Freeman and Katan 1997; Rahman et al. 2013). Anthracnose disease of strawberry remains a challenging disease to manage, even with the use of cultural practices to reduce primary inoculum and fungicide sprays to limit pathogen reproduction (Louws and Rahman 2012; MacKenzie et al. 2009). In NC, the primary cultivars in production are cultivars Chandler and Camarosa, which were developed by the University of California, Davis. These cultivars are widely adapted throughout $\mathrm{NC}$ and can produce excellent yield and fruit quality in a plasticulture production system (Poling 1993). However, continuous use of Chandler and Camarosa, which are highly susceptible to ACR and AFR, and recurrent introduction of pathogen inoculum within the production systems have increased the risk of anthracnose epidemics in strawberry production in NC to unprecedented levels (Rahman et al. 2013). Asymptomatic planting stocks carrying quiescent Colletotrichum infections are often the most important source of inoculum in fruiting fields and have been implicated in many anthracnose epidemics in the southeastern United States (Delp and Milholland 1980; Leandro et al. 2003; Louws and Rahman 2012; MacKenzie et al. 2009; Poling 2008; Smith 2008). C. gloeosporioides can cause up to 50 to $80 \%$ plant loss in nurseries and 40 to $50 \%$ yield loss in fruit production fields (Howard et al. 1992; Xie et al. 2010). Similarly, 50 to $80 \%$ fruit losses owing to $C$. acutatum have been reported (Howard et al. 1992; Rahman et al. 2013). Hemibiotrophic plant pathogens initially form an association with living cells of the host, much like biotrophs (derive nutrients from living cells), and then, in the later stage, they become necrotrophs (cause the death of the host tissues and obtain energy from the dead cells) (Oliver and Ipcho 2004). Although these terms have been well described, disagreements about which pathogens fall into which classes have some limitations. Based on genomic and transcriptomic analyses, hemibiotrophic infection (HBI) was defined as an early stage of infection or the symptomless biotrophic phase (quiescent or latent) and a late necrotrophic stage, which was characterized by tissue 
degradation and disease symptoms (De Silva et al. 2017; Gan et al. 2013). HBI is attributed to the presence of preformed antifungal compounds in host tissues and activation of a series of small secreted proteins, secondary metabolite synthesis genes, proteases, and carbohydrate-degrading enzymes (Oliver and Ipcho 2004). In strawberry industries, bare roots or plug plants are produced from mother nurseries that are grown during hot and humid summer, favoring dissemination and multiplication of Colletotrichum spp. These fungal pathogens can infect host tissues and remain latent or dormant epiphytically or endophytically on leaves or petioles (Freeman et al. 2001) throughout the nursery period, and they can serve as inoculum in fruiting fields (Leandro et al. 2001). Understanding the lifestyle patterns of Colletotrichum spp. and the dynamic state of their interactions with their hosts has important implications for disease resistance breeding.

Host plant resistance is one of the most sustainable and effective strategies for managing anthracnose disease of strawberry. However, anthracnose-resistant cultivars are either unavailable or do not meet the horticultural and fruit quality standards required by the industry (Delp and Milholland 1980; Leandro et al. 2003; MacKenzie et al. 2009; Poling 2008; Smith 2008). Relatively limited research has been conducted to investigate and compare resistance to hemibiotrophic Colletotrichum infection in strawberry foliage and crown tissue. Rahman et al. (2013) evaluated 14 strawberry genotypes for resistance to HBI and AFR caused by $C$. acutatum and found that resistance to HBI was not correlated to AFR resistance. Earlier studies indicated that foliar resistance to hemibiotrophic Colletotrichum infection in strawberry is considered rate-reducing resistance (Jacobs 2015; Rahman et al. 2013), a form of partial resistance sensu Parlevliet (1979). Rate-reducing resistance is defined as a form of resistance that retards the multiplication or development of the pathogen in the crop (Parlevliet 1979). This kind of resistance is called partial (i.e., never complete), but it is usually durable (Tooley and Grau 1982). Resistance is expressed through reduced infection frequency (IF), longer latent period (LP), reduced spore production (SP) and lesion area, shorter infectious period, or a combination of these. These components can be quantified to predict cultivar resistance (Zadoks and Schein 1979). Unfortunately, the procedures involved are laborious and time consuming. Therefore, plant pathologists and breeders prefer to use the established procedures for quantitative estimates of infection rate $(r)$, disease incidence (DI), disease severity (DS), and area under disease progress curve (AUDPC) over time. Importantly, DI and DS combine the effects of IF, LP, and SP (Parlevliet 1979; Tooley and Grau 1982).

Traditionally, plant DS has been scored with visual inspection and categorized according to a discrete scale (Bock et al. 2010). Plant disease symptoms (relative to pathogen multiplication or growth development) were also characterized visually or measured indirectly on the basis of changing in leaf color (Wijekoon et al. 2008). The precise quantification of these parameters is an important element of plant-pathogen interactions. Different imaging technologies and computer software have been developed and used for improving the accuracy and precision of plant disease symptoms and quantification of foliar damage owing to plant pathogens (Nutter et al. 2006). For asymptomatic Colletotrichum HBI in strawberry, the severity of fungal colonization in leaf tissue was estimated by the herbicide 1,1'-dimethyl-4'4-bipyridinium dichloride (paraquat) (Cerkauskas and Sinclair 1982; Rahman et al. 2013) and real-time quantitative PCR (qPCR) assays (Garrido et al. 2009). Lately, colonization of strawberry leaf tissue by Colletotrichum spp. has been measured using semiautomated image analysis of discolored leaf areas (AbdEl-Haliem 2012; Jacobs 2015). The degree of anthracnose resistance can be estimated by assessing DI and DS (Rahman et al. 2013; Smith and Spiers 1982). DI is the proportion of diseased plant units (Madden et al. 2007). In the case of anthracnose, DI is the proportion of diseased strawberry leaves or fruits. The degree of infection on a leaf is a measure of DS, and it is typically measured as the percentage of leaf area covered by sporulating lesions or percentage of sporulating leaf area (PSLA). AUDPC scores were calculated for comparing disease intensity over time across genotypes (Campbell and Madden
1990). In anthracnose, relative area under disease progress curve (rAUDPC) scores are expressed as percentage-days or the daily accumulation of PSLA (Fry 1978; Jacobs 2015).

A major challenge with the anthracnose disease is that resistance to ACR is not correlated with resistance to AFR (Ballington et al. 2002; Gupton and Smith 1991; MacKenzie et al. 2006; Osorio et al. 2014; Smith and Spiers 1982). However, the hemibiotrophic stage is common for both Colletotrichum species during their pathogenic lifecycle (Arroyo et al. 2005; Cannon et al. 2012; Gan et al. 2013; Muench et al. 2008; Peres et al. 2005; Perfect et al. 1999). We hypothesize that resistance to $\mathrm{HBI}$ owing to C. acutatum and C. gloeosporioides can be correlated in strawberry leaf tissue, providing a shared rate-reducing mechanism to reduce overall ACR and AFR epidemics by restricting the spread and buildup of inoculum in nurseries and fruiting fields. In addition, we hypothesize that resistance to C. gloeosporioides in leaf tissue (i.e., HBI) may not be correlated with resistance in crown tissue (e.g., ACR). The main objective of this study was to assess resistance to HBI of $C$. acutatum and $C$. gloeosporioides after foliar inoculation of a panel of strawberry genotypes. We also subsequently inoculated strawberry crowns to evaluate these genotypes for resistance to ACR caused by $C$. gloeosporioides. Based on our experience, resistance to Colletotrichum spp. is controlled by multiple genes (Ballington et al. 2002; Jacobs et al. 2019; Osorio et al. 2014). Thus, we evaluated disease resistance to HBI and ACR in strawberry cultivars/lines under controlled environments to provide reproducibility of the main results.

\section{Materials and Methods}

Characterizing isolates of $C$. acutatum and $C$. gloeosporioides by real-time qPCR assay. The isolates of $C$. acutatum and $C$. gloeosporioides used in this study were collected from strawberry fields in NC (Table 1), and they were initially identified by morphological attributes, such as colony color, and growth rate on Difco potato dextrose agar (PDA) as described previously (Gunnell and Gubler 1992; Smith and Black 1990). Identification was further confirmed using species-specific primers and probes designed for TaqMan real-time PCR (Garrido et al. 2009). Briefly, $200 \mathrm{mg}$ of mycelium was collected by scraping the surface of each plated pure culture with a scalpel. Mycelia were placed into 2.0-ml microcentrifuge tubes, freeze dried, and ground to a fine powder using a sterile glass rod. A modified cetyltrimethylammonium bromide DNA extraction protocol was used to extract genomic DNA from each fungal isolate as described previously (Murray and Thompson 1980). DNA yield and quality were checked with a NanoDrop 2000 spectrophotometer, and samples were stored at $-20^{\circ} \mathrm{C}$. All qPCR conditions and cycles were similar as described previously (Garrido et al. 2009). The cycle threshold $\left(\mathrm{C}_{\mathrm{T}}\right)$ value of each $\mathrm{qPCR}$ assay was calculated using the 7500 Software Version 3.2 (Life Technologies).

MLSA. To confirm genetic relationships of the test isolates of $C$. acutatum (Ca34, Ca40, and $\mathrm{Ca} 89)$ from $\mathrm{NC}$, four target gene regions GAPDH, ITS, MAT1-2, and TUB (Boroncelli et al. 2015) were sequenced, and for $C$. gloeosporioides isolates $(\mathrm{Cg} 28, \mathrm{Cg} 58$, and Cg84), three sequence loci GAPDH, ITS, and TUB (Weir et al. 2012) were sequenced. For sequencing of $C$. acutatum isolates, all PCR cycles and conditions were similar as described previously (Boroncelli et al. 2015). PCR amplification of the target regions of C. gloeosporioides isolates was carried out as described before (Weir et al. 2012). Briefly, $6 \mu \mathrm{l}$ of each purified PCR product was sequenced at the Genomic Sciences Laboratory, NC State University (Raleigh, NC). Consensus sequences were generated using Geneious 10.1 (https://www.geneious.com/tutorials) and aligned using MUSCLE (https://www.ebi.ac.uk/Tools/msa/muscle/). Multiple sequence alignments were exported to MEGA 7.0 (Kumar et al. 2016), where best-fit substitution models were calculated for each separate sequence dataset. Sequences of the amplified regions of the isolates of both C. acutatum and C. gloeosporioides were deposited in GenBank (accession nos. MH818318 to MH818323 and MH887544 to MH887555). Additionally, sequences of the 11 species within the $C$. acutatum species complex (Boroncelli et al. 2015) and the 18 species within the $C$. gloeosporioides species 
complex (Weir et al. 2012) were retrieved from GenBank. The genetic distance model Tamura-Nei was used to determine the genetic divergence between the isolates. Additional phylogenetic analysis was performed by the Jukes-Cantor neighbor-joining trees, and maximum parsimony analyses $(100,000$ replicates) were separately performed using Geneious 10.1.

Assessing resistance to $\mathrm{HBI}$ and ACR in strawberry leaf tissues based on visual assessment and digital image analysis. Eight advanced breeding lines NCS 10-019, NCS 10-028, NCS 10-037, NCS 10-080, NCS 10-086, NCS 10-092, NCS 10-142, and NCST 10-032 developed by the NC State University strawberry breeding program were selected based on the preliminary studies and evaluated. Two cultivars Chandler and Camarosa were used as susceptible checks. Disease-free runner tips of each genotype were collected from a field planting at the Piedmont Research Station in Salisbury, $\mathrm{NC}$ and brought to a greenhouse in Kannapolis, NC for propagation. Tips were planted in 50-cell plug trays containing Fafard 3B mix (Sun Gro Horticulture) and rooted under periodic mist (30-s duration and 10-min interval) in a $21 \pm 5^{\circ} \mathrm{C}$ greenhouse for 1 week until roots developed. After 2 additional weeks of growth and management, plugs were transplanted into $10-\mathrm{cm}$ pots containing Fafard $3 \mathrm{~B}$ potting mix and grown in a $25 \pm 5^{\circ} \mathrm{C}$ greenhouse. The plants were hand watered daily and fertilized with a solution of Jack's Professional LX Ca-Mg 15-5-15 fertilizer (JR Peters Inc.) via a Dosatron injector system calibrated to dispense $100 \mathrm{ppm} \mathrm{N}$. The experiment was arranged in a split plot randomized complete block design (RCBD) with eight replications, and 10 genotypes (including susceptible checks) were randomized to four-plant plots within each replication. Thirty-two clonal plants of each genotype were considered an experimental unit and inoculated by each species or water as controls. To assess strawberry genotypes, three isolates each of $C$. acutatum (Ca34, Ca40, and Ca89) and C. gloeosporioides (Cg28, Cg58, and $\mathrm{Cg} 84$ ) were confirmed using qPCR based on SYBR Green assay (Garrido et al. 2009) (Table 1). These isolates were the most aggressive in pathogenicity assays (data not shown). Fresh cultures were made from colonies on PDA grown out from long-term storage at $-80^{\circ} \mathrm{C}$ of each isolate by transferring mycelial plugs with a sterile needle to new PDA plates. Ten plates of each isolate were prepared, and cultures were incubated at $25^{\circ} \mathrm{C}$ for 14 days under $12 \mathrm{~h}$ of fluorescent light. Inoculum suspensions were created by agitating sporulating plates with sterile distilled water and then, filtering through a doubled layer of cheesecloth. The mixed inoculum was prepared by adjusting the inoculum concentration of each isolate to $1.0 \times$ $10^{6}$ conidia per milliliter using a hemocytometer before combining by species. Plants were spray inoculated with a hand sprayer (Solo model 419) until runoff and kept in a greenhouse at $25 \pm 5^{\circ} \mathrm{C}$. Plants inoculated with sterile distilled water served as untreated controls
(UTCs). Samples consisted of four individual leaflets, which were arbitrarily collected from each four-plant plot. Inoculated leaflets were collected $0,3,6,9,12,15,18$, and 21 days after inoculation (DAI) and stored at $4^{\circ} \mathrm{C}$.

The herbicide paraquat was used to induce senescence of leaf tissue and spur the production of salmon-colored acervuli from quiescent foliar infections as described previously (Cerkauskas and Sinclair 1982; Jacobs 2015; Rahman et al. 2013). Briefly, six trifoliate leaves per cultivar or line were surface sterilized by immersing in $70 \%$ ethanol for $15 \mathrm{~s}$ and $10 \%$ bleach for $60 \mathrm{~s}$, and then, they were rinsed twice in sterile distilled water. Leaflets were then immersed for $1 \mathrm{~min}$ in a 1:50 paraquat solution and rinsed a final time in sterile distilled water. Plastic zipper bags, $26 \times 30 \mathrm{~cm}$, lined with a double layer of paper towels were used for incubation and acervuli development. Paraquat-treated leaves were placed adaxial side up in a single layer inside bags and left unsealed to allow gas exchange. Bags were incubated in a growth room (Harris Environmental Systems Inc.) at $25^{\circ} \mathrm{C}$ and $40 \%$ relative humidity. Samples were assessed for visual scoring and image analysis $96 \mathrm{~h}$ after incubation. AUDPC scores were calculated for each strawberry genotype from average PSLA as reported previously (Campbell and Madden 1990). AUDPC is represented by the equation:

$$
\mathrm{AUDPC}=\sum_{i=1}^{n-1}\left(\frac{y_{i}+y_{i+1}}{2}\right)\left(t_{i+1}-t_{i}\right)
$$

where $t$ is time in days between each sample date, $y$ is the PSLA at each sample date, and $n$ is the total number of sample dates (Shaner and Finney 1977). AUDPC scores are expressed as percentage-days or the daily accumulation of PSLA. A macro plugin called Phenotype Quant was used to measure visible disease symptoms (Fig. 1) using the imaging software ImageJ (Abd-El-Haliem 2012). Furthermore, Phenotype Quant uses filters to quantify the area (in pixels) of diseased leaf tissue and total leaf tissue, distinguishing each by userdefined colors (Abd-El-Haliem 2012). These two values were used to calculate the percentage of total leaf area covered by the sporulating pathogen in this study. Imaging software was tested in addition to direct visual estimation to determine if it could be used to increase the accuracy and precision of PSLA measurements. The colors of $C . a c u-$ tatum and $C$. gloeosporioides acervuli (orange to brown) were too similar in color to paraquat-treated leaves (copper to brown). Therefore, thresholds were adjusted to accurately estimate PSLA of a single image, but sample-to-sample variation in background leaf color did not accommodate automated quantification of a set of images. Samples were placed on a blue background with a plot number and sample date visible. PSLA was visually estimated using a linear scale

Table 1. Characterization of isolates of Colletotrichum acutatum and Colletotrichum gloeosporioides from North Carolina using quantitative real-time PCR assay

\begin{tabular}{|c|c|c|c|c|c|c|c|c|}
\hline \multirow[b]{2}{*}{ Isolate no. } & \multirow[b]{2}{*}{ Location } & \multirow[b]{2}{*}{ Tissue of origin } & \multirow[b]{2}{*}{ Putative identification ${ }^{a}$} & \multicolumn{2}{|c|}{ C. acutatum } & \multicolumn{2}{|c|}{ C. gloeosporioides } & \multirow[b]{2}{*}{ Real-time PCR outcome } \\
\hline & & & & $\mathrm{C}_{\mathrm{T}}$ mean $^{\mathrm{b}}$ & $\mathrm{C}_{\mathrm{T}} \mathrm{SD}^{\mathrm{c}}$ & $\mathrm{C}_{\mathrm{T}}$ mean & $\mathrm{C}_{\mathrm{T}} \mathrm{SD}$ & \\
\hline $\mathrm{UTC}^{\mathrm{d}}$ & $\mathrm{N} / \mathrm{A}^{\mathrm{e}}$ & N/A & N/A & $--^{f}$ & - & - & - & N/A \\
\hline $\mathrm{Cg} 28$ & Sanford, NC & Crown & C. gloeosporioides & - & - & 23.12 & 0.30 & C. gloeosporioides \\
\hline Ca34 & Bunn, NC & Leaf-quiescent & C. acutatum & 20.53 & 0.22 & - & - & C. acutatum \\
\hline $\mathrm{Ca} 40$ & Bunn, NC & Clinic sample & C. acutatum & 23.93 & 0.28 & - & - & C. acutatum \\
\hline $\mathrm{Cg} 46$ & Wake Co., NC & Leaf-quiescent & C. gloeosporioides & - & - & 23.16 & 0.06 & C. gloeosporioides \\
\hline $\mathrm{Cg} 58$ & Sanford, NC & Crown & C. gloeosporioides & - & - & 23.10 & 0.29 & C. gloeosporioides \\
\hline $\mathrm{Cg} 84$ & Franklin, NC & Crown & C. gloeosporioides & - & - & 24.36 & 0.09 & C. gloeosporioides \\
\hline $\mathrm{Ca} 89$ & Salisbury, NC & Fruit & C. acutatum & 21.14 & 0.31 & - & - & C. acutatum \\
\hline $\mathrm{Ca} 90$ & Kannapolis, NC & Petiole & C. acutatum & 20.33 & 0.31 & - & - & C. acutatum \\
\hline Cg91 & Kannapolis, NC & Leaf-quiescent & C. gloeosporioides & - & - & 25.40 & 0.24 & C. gloeosporioides \\
\hline $\mathrm{Cg} 92$ & Salisbury, NC & Leaf-quiescent & C. gloeosporioides & - & - & 24.01 & 0.26 & C. gloeosporioides \\
\hline
\end{tabular}

a Putative identification based on host symptomology and conidia morphology.

${ }^{\mathrm{b}} \mathrm{C}_{\mathrm{T}}$ mean, mean cycle threshold score of three technical replicates.

${ }^{c} C_{T} S D$, mean cycle threshold standard deviation of three technical replicates.

${ }^{\mathrm{d}}$ UTC, untreated control using sterile distilled water.

e N/A, not applicable.

${ }^{\mathrm{f}}$ Cells with dashed lines indicate that the target was not detected or did not exceed the threshold. 
of 0 to $100 \%$. Each sample was photographed using a Panasonic Lumix DMC-ZS10 point-and-shoot camera (Panasonic Corporation) under standardized light. Processed images were analyzed using the Phenotype Quant macro in ImageJ to compute the diseased and total leaf areas. The program analyzed each image in succession and compiled a list of output values from each image. PSLA was calculated from ImageJ data in Microsoft Excel 2013 (Microsoft Corporation) as follows:

$$
\text { PSLA }=\left(\frac{\text { Diseased leaf area }}{\text { Total leaf area }}\right) \times 100
$$

The relationships between PSLA and visual estimates were analyzed using the correlate procedure (PROC CORR) of Statistical Analysis System (SAS) Version 9.4 (SAS Institute). A square root transformation was applied to nonnormal ImageJ data, and transformed PSLA values were used for analysis. A square root transformation was applied to nonnormal AUDPC data, and mean transformed values were used for data analysis. Data were analyzed using the generalized linear mixed model procedure (PROC GLIMMIX) of SAS. Replication was considered a random effect, and genotype was considered a fixed effect. Means separation and significant effects were generated using the DIFF LINES option to produce $\mathrm{T}$ groupings of least squares means $(P \leq 0.05)$.

Comparison and correlation between HBI and ACR. Eighteen strawberry cultivars and lines were selected based on previous responses to anthracnose infections and included 11 lines from the NC State University strawberry breeding program and seven commercial cultivars. The cultivar Chandler was used as a susceptible check. Four plug plants of each genotype were potted into 7.5-liter pots containing Fafard 3B mix (Sun Gro Horticulture) to serve as mother plants for runner production. Mother plants and runners were produced in a greenhouse as described above. The experiment was laid out in a split-split plot RCBD with four replications. Each replication was divided into three main plots, to which $C$. acutatum, $C$. gloeosporioides, or UTC main plot treatments were randomly assigned. Main plots were each divided into 18 split plots, to which three clonal plants of each genotype were randomly assigned. Leaf samples were collected 7, 14, 21, and 28 DAI. Sample dates were treated as a split-split plot factor, because these within-plot measurements were independent, with different leaves sampled on each sample date. This foliar experiment was conducted twice: from 5
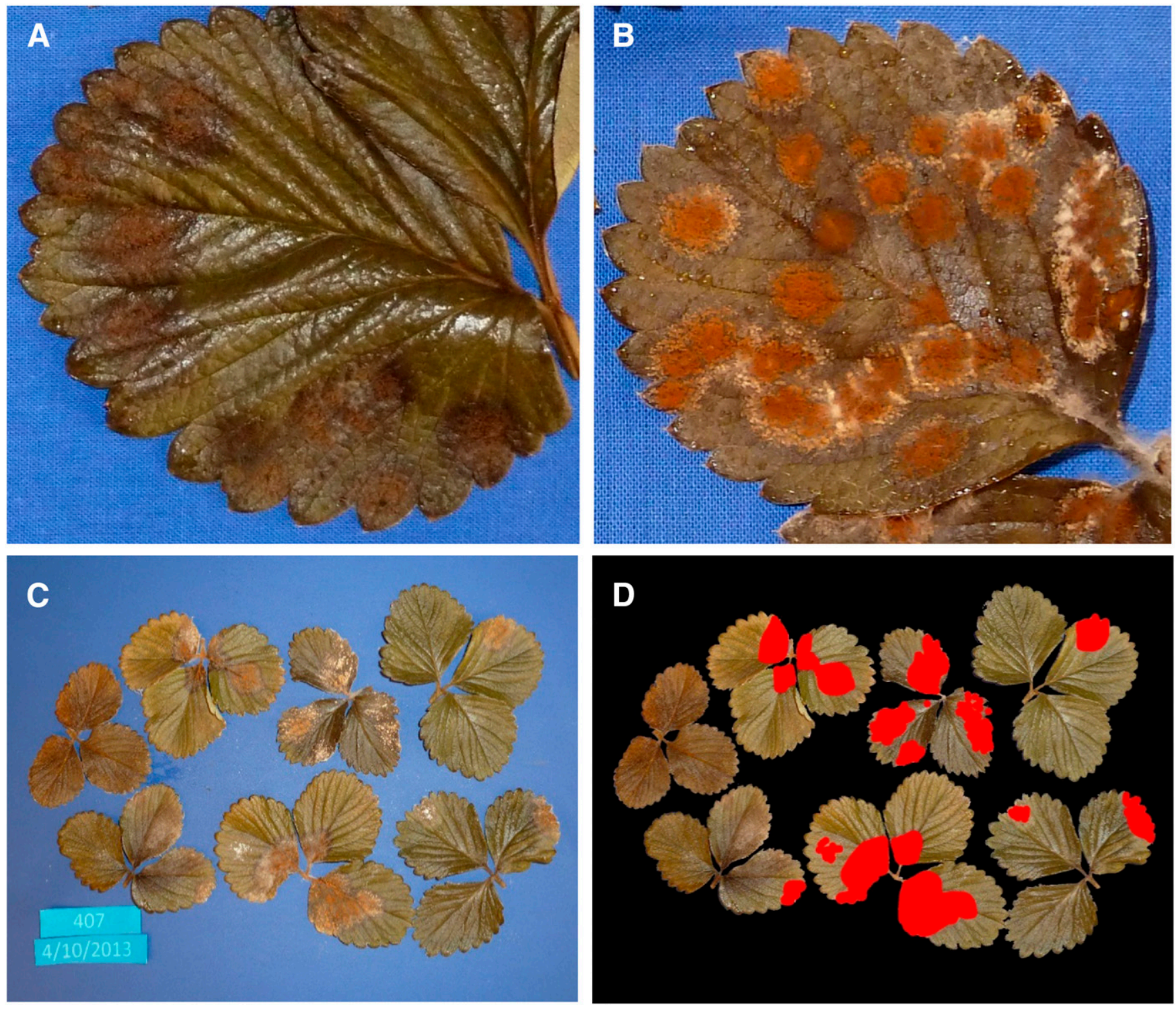

Fig. 1. The appearance of Colletotrichum acervuli in paraquat-treated strawberry leaves. A, Acervuli and conidia of Colletotrichum gloeosporioides on the leaf of North Carolina State University advanced selection NCS 10-107 appearing brown with dark borders. B, Acervuli and conidia of Colletotrichum acutatum on the leaf of the cultivar NCS 10-107 appearing orange with light borders. C, Acervuli and conidia of $C$. acutatum on the leaf of cultivar Chandler appearing orange with light borders. D, Percentage sporulating leaf area using image analysis. 
February 2014 to 5 March 2014 and again, from 16 April 2014 to 14 May 2014. Plants screened for foliar resistance to $C$. gloeosporioides were then evaluated for resistance to ACR by applying $C g$ inoculum directly to the crown. The crown evaluation was conducted twice: from 12 March 2014 to 21 May 2014 and again, from 4 June 2014 to 13 August 2014. Treatments were randomly assigned to main plots and split plots separately between experiments, but they were carried over from foliar to crown evaluations of the same experiment. Inoculum preparation, inoculation, fungal colonization assessment on leaf tissue, and image analysis used to measure PSLA were conducted as described above. For crown inoculations, $3 \mathrm{ml}$ of inoculum was applied directly to the crown of each plant with a hand sprayer (Solo model 419). Individual plants were evaluated for ACR symptoms $7,14,21,28,35,42,49,56,63$, and $70 \mathrm{DAI}$. ACR severity was assessed using a disease index of $0=$ no wilt, $1=$ youngest leaf wilted, $2=25 \%$ of leaves wilted, $3=50 \%$ of leaves wilted, $4=$ $75 \%$ of leaves wilted, and $5=$ complete collapse. Infected crowns were periodically examined by making a cross-section through the crown tissue to observe internal ACR symptoms. If symptoms were nontypical of ACR, diseased crown tissues were plated onto PDA for examining colony and conidia morphology. rAUDPC was calculated for each genotype by dividing AUDPC scores (Shaner and Finney 1977) by the maximum potential AUDPC for the experiment (Fry 1978). The maximum potential AUDPC is the AUDPC score that would be reached if the disease was assessed at maximum severity (5.0 split plot average) on every sampling date. Homogeneity of variance was assessed through diagnostic graphic displays of residual versus fitted values. Normality and homogeneity of variance of the distribution were improved for statistical analysis through the transformation of rAUDPC data using the formula $\sin ^{-1} \sqrt{\text { rAUDPC}}$. Transformed rAUDPC values were analyzed using PROC GLIMMIX in SAS. Significant effects were compared using $T$ grouping of least squares means $(P \leq 0.05)$, which were back transformed for comparison. To measure rate-reducing resistance, DS in leaf and crown tissues inoculated with $C$. gloeosporioides was compared using transformed PSLA and rAUDPC means. Plot averages were calculated for each variable using PROC MEANS in SAS. The relationship between leaf and crown phenotypes was examined using PROC CORR. Pearson's correlation coefficient was computed to determine the strength of correlation between resistance to C. gloeosporioides in leaf and crown tissues. Average PSLA and rAUDPC

Table 2. Analysis of variance of the effects of the experiment, treatment $(\mathrm{Col}$ letotrichum species), genotype, and days after inoculation (DAI) on the severity of hemibiotrophic foliar infections (disease severity was assessed using image-based analysis as percentage of sporulating leaf area)

\begin{tabular}{|c|c|c|c|}
\hline Source of variation & $\begin{array}{l}\text { Degree of freedom } \\
\text { (df) }\end{array}$ & $\boldsymbol{F}$ & $P>F$ \\
\hline Experiment & 1 & 0.31 & 0.5982 \\
\hline $\begin{array}{l}\text { Treatment (Colletotrichum } \\
\text { species) }\end{array}$ & 1 & 11.07 & $0.0159^{\mathrm{a}}$ \\
\hline Experiment $\times$ treatment & 1 & 3.41 & 0.1145 \\
\hline Genotype $^{\mathrm{b}}$ & 17 & 16.14 & $<0.0001^{\mathrm{c}}$ \\
\hline Experiment $\times$ genotype & 17 & 2.40 & $0.0021^{\mathrm{d}}$ \\
\hline Treatment $\times$ genotype & 17 & 2.26 & $0.0040^{\mathrm{d}}$ \\
\hline Experiment $\times$ treatment $\times$ genotype & 17 & 1.03 & 0.4321 \\
\hline DAI & 3 & 180.75 & $<0.0001^{\mathrm{c}}$ \\
\hline Experiment $\times$ DAI & 3 & 10.43 & $<0.0001^{\mathrm{c}}$ \\
\hline Treatment $\times$ DAI & 3 & 31.15 & $<0.0001^{\mathrm{c}}$ \\
\hline Experiment $\times$ treatment $\times$ DAI & 3 & 16.82 & $<0.0001^{\mathrm{c}}$ \\
\hline Genotype $\times$ DAI & 51 & 1.48 & $0.0187^{\mathrm{a}}$ \\
\hline Experiment $\times$ genotype $\times$ DAI & 51 & 1.18 & 0.1917 \\
\hline Treatment $\times$ genotype $\times$ DAI & 51 & 0.74 & 0.9130 \\
\hline $\begin{array}{l}\text { Experiment } \times \text { treatment } \times \text { genotype } \\
\times \text { DAI }\end{array}$ & 51 & 0.81 & 0.8275 \\
\hline
\end{tabular}

\footnotetext{
${ }^{a}$ Level of significance: significant at $P<0.05$.

${ }^{\mathrm{b}}$ Eighteen strawberry genotypes were evaluated.

${ }^{\mathrm{c}}$ Level of significance: significant at $P<0.001$.

d Level of significance: significant at $P<0.005$.
}

scores were calculated for each genotype across both experiments, and their relationship was plotted.

\section{Results}

Characterizing isolates of $C$. acutatum and $C$. gloeosporioides by real-time qPCR assay. The morphologies of $C$. acutatum and C. gloeosporioides isolates analyzed in this study were identical to those reported previously (Gunnell and Gubler 1992; Smith and Black 1990). C. gloeosporioides colonies were gray to olive in color, with areas of visible salmon-colored acervuli. Colonies expanded rapidly on PDA at $25^{\circ} \mathrm{C}$ and reached the edge of plates in $<7$ days. Conidia were cylindrical, with both ends rounded. C. acutatum colonies were typically beige to pink in color, turning darker shades of pink to olive over time. C. acutatum colonies expanded at only a fraction of the rate of $C$. gloeosporioides on PDA at $25^{\circ} \mathrm{C}$, taking $\sim 12$ to 14 days to reach the edge of plates. Conidia were fusiform and smaller than those of $C$. gloeosporioides; however, they produced more abundantly. Furthermore, species-level identification of colony and conidia morphology was supported by qPCR assay. The speciesspecific primers successfully differentiated the isolates examined. Positive species identification was indicated by rapid signal amplification (low $\mathrm{C}_{\mathrm{T}}$ mean values) and consistent response among technical replicates (low $\mathrm{C}_{\mathrm{T}}$ standard deviation). All isolates tested by qPCR assays were confirmed to be either C. acutatum or C. gloeosporioides (Table 1). Some of these isolates were used for additional experiments.

MLSA. Phylogenetic trees generated using combined multiple gene sequence data of the three isolates of either $C$. acutatum or C. gloeosporioides from NC were compared with other isolates associated with different hosts and species within the $C$. acutatum species complex and C. gloeosporioides species complex. Based on cluster analysis and bootstrap values, three isolates of $C$. acutatum $(\mathrm{Ca} 34$, $\mathrm{Ca} 40$, and $\mathrm{Ca}$ 89) from $\mathrm{NC}$ were detected within a subcluster of the isolates of $C$. nymphaeae from strawberry from different countries (Supplementary Fig. S1). Likewise, the alignment of the concatenated three genes when compared with respect to their performance in recognition of three isolates of C. gloeosporioides $(\mathrm{Cg} 28, \mathrm{Cg} 58$, and $\mathrm{Cg} 84$ ) from $\mathrm{NC}$ revealed that two isolates $\mathrm{Cg} 28$ and $\mathrm{Cg} 84$ formed a single subcluster, whereas one isolate $\mathrm{Cg} 58$ was detected in another subcluster representing Colletotrichum siamense (Supplementary Fig. S2).

Comparison between HBI and ACR based on visual assessment and digital image analysis. Paraquat assays of plant material before inoculation indicated no prior quiescent infections present in these plants. Periodic checks of Colletotrichum species throughout the experiment found no deviations from expected species in samples examined microscopically and/or plated and examined in culture. Additionally, direct visual identification of species was possible owing to the difference in the color of $C$. acutatum and C. gloeosporioides acervuli on paraquat-treated leaves. C. gloeosporioides acervuli typically appeared brown with dark borders, whereas $C$. acutatum acervuli were orange with light borders (Fig. 1). A linear relationship was observed between Image $J$ data and visual estimation of sporulating leaf area. The correlation between data collection methods was best described by a linear equation, and it was high $\left(y=0.7341 x+5.008 ; R^{2}=0.82\right)$, but visual estimates generally underestimated the actual DS calculated by ImageJ, especially at higher severities. Mean PSLA scores owing to the experiment were not significantly different (Table 2) $(P=0.5982)$, allowing data of the two experiments to be pooled. There was a significant effect of DAI $(P<0.0001)$ (Table 2$)$. The overall mean for $C$. gloeosporioides $(16.5 \%)$ was significantly lower $(P=0.0159)$ than that of $C$. acutatum $(18.8 \%)$. The interaction between genotype and fungal species (treatment) was significant, and this was probed further. Among the 18 genotypes evaluated, the 3 genotypes (cultivar Festival $[P=$ 0.0084], cultivar NCS 11-107 [ $P=0.0033]$, and cultivar Treasure $[P<0.0001])$, were found to have significantly different responses between Colletotrichum species; however, all other genotypes were not significantly different between Colletotrichum species (Fig. 2). There were significant effects of genotype $(P<0.0001)$ (Table 2$)$. 


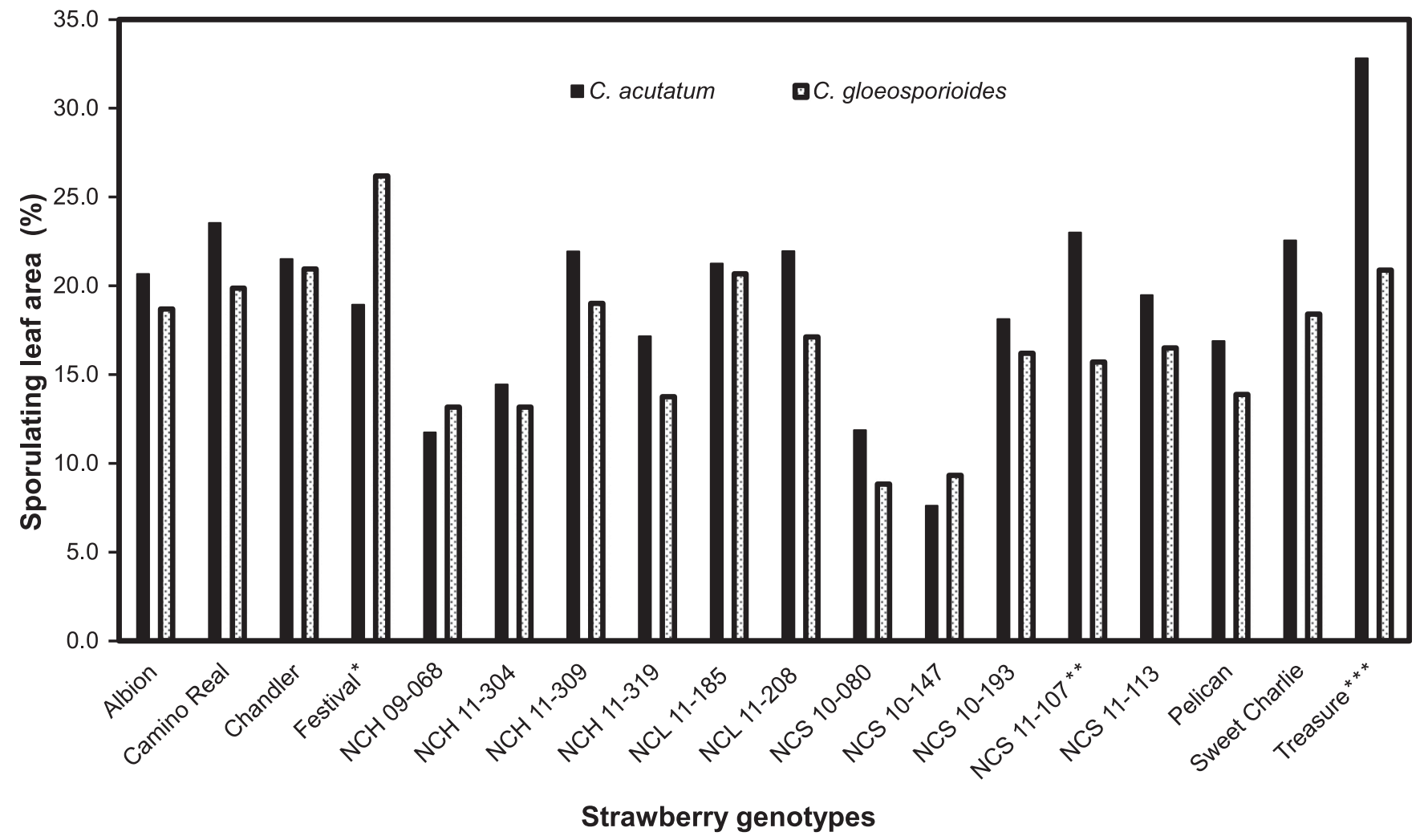

Fig. 2. Mean percentage of sporulating leaf area at each level of genotype infected by Colletotrichum acutatum and Colletotrichum gloeosporioides. Genotypes with significant differences in treatment response are denoted. *Significant at $P<0.05$; ${ }^{* *}$ Significant at $P<0.005$; ${ }^{* *}$ Significant at $P<0.001$.

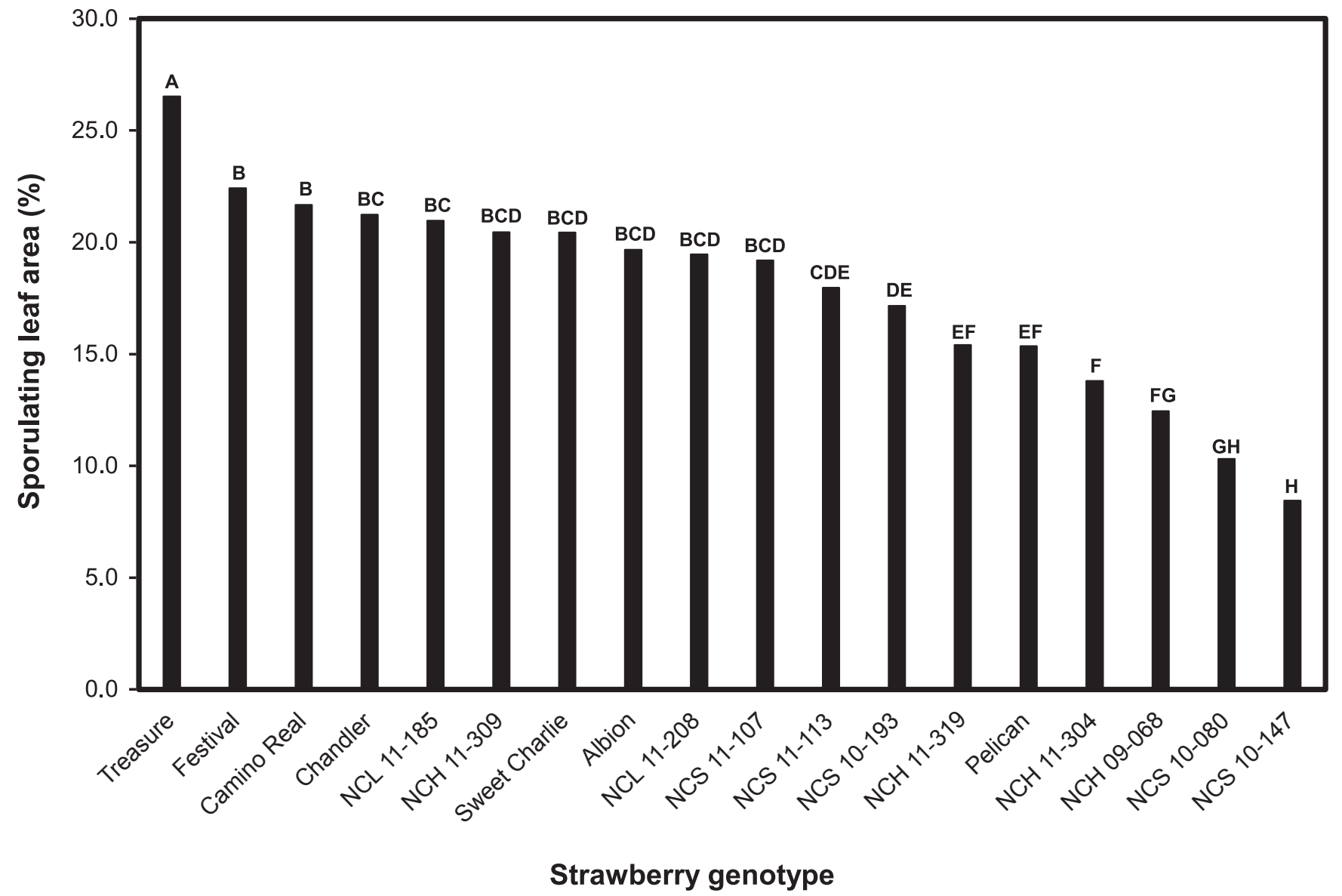

Fig. 3. Mean percentage of sporulating leaf area for 18 genotypes averaged over both Colletotrichum gloeosporioides and Colletotrichum acutatum. The ranking appears above each genotype. Genotypes with the same letter are not significantly different $(P \leq 0.05)$. 
Genotype means (averaged over both Colletotrichum species) ranged from NCS 10-147 with 8.5 to Treasure with $26.5 \%$ (Fig. 3). Mean PSLA scores were impacted by DAI, and the interaction of experiment by DAI resulted from significant differences in the simple effect of experiment on PSLA means 7 DAI $(P=0.0541)$ and $21 \mathrm{DAI}(P=0.0256)$; the other sample dates had similar PSLA values. The interaction of DAI with treatment and genotype seemed to be owing to low levels of colonization on some selections (e.g., NCS 10-147) compared with high levels of colonization over time on susceptible lines (e.g., Treasure) and differential responses of the two Colletotrichum species on selected lines (e.g., Festival versus NCS 11-107) (Fig. 2). Pearson's correlation coefficient was minimally correlated $(r=$ $0.4251, P<0.0001)$ between $C$. acutatum and $C$. gloeosporioides HBIs across genotypes.

For ACR evaluation, minor wilt was observed in only a small percentage of plants, and no plants exhibited symptoms $>2$ rating after the HBI study. After the supplemental inoculations into the crown tissue, significant wilt was observed by 7 DAI and increased steadily after that point. C. acutatum-inoculated plants showed symptoms of stunting (data not shown) rather than the distinct wilting seen in $C$. gloeosporioides-inoculated plants. The transformed rAUDPC data found a major effect of experiment $(P<0.0001)$ and an interaction of experiment by genotype $(P<0.0001)$. A significant effect of genotype $(P<0.0001)$ was examined through the $T$-letter grouping of genotype least squares means, which were back transformed to rAUDPC means for comparison (Fig. 4). rAUDPC genotype means encompassed nearly the entire range from 0.0 to 1.0 based on the ratio of AUDPC to maximum potential AUDPC. The most susceptible genotypes were cultivar Camino Real (0.93), cultivar Albion (0.89), and Chandler (0.88). The most resistant genotype was cultivar Pelican (0.05). Correlation between foliar and crown tissue resistance to $C$. gloeosporioides was positive but small $(r=0.2430, P<0.0001)$ (Fig. 5).

\section{Discussion}

We conducted a series of experiments in controlled environments in a greenhouse to determine the genetic relationships of the pathogens causing anthracnose disease on strawberry in NC. We then compared the accuracy of visual scoring and digital image analysis to assess resistance to both $C$. acutatum and C. gloeosporioides in the leaf and crown tissues of strawberry cultivars and breeding lines. We used MLSA to generate sequence data from the target genomic regions and compared these with characterized species within the C. acutatum complex (Boroncelli et al. 2015) and within the C. gloeosporioides complex (Weir et al. 2012). Based on the concatenation of the different sequence loci, the $C$. acutatum isolates from $\mathrm{NC}$ were closely related to $C$. nymphaeae within the $C$. acutatum species complex, confirming that these sequence loci are useful for identification and discrimination of species of C. acutatum complex (Boroncelli et al. 2015). Similarly, the isolates of $C$. gloeosporioides from $\mathrm{NC}$ were found to be more closely related to $C$. siamense than other species within the C. gloeosporioides species complex (Weir et al. 2012).

Our comparison of visual and image-based analyses of PSLA found a high degree of correlation between these methods, suggesting little advantage to image analysis until this process can be further automated to better account for image-to-image variation. The correlation and associations between HBIs and ACR had small treatment effects, and they could be explained genetically if resistance to HBI in strawberry leaves is only controlled by minor genes. This narrow range could also be explained by the relatively small sample size of host genotypes. A much broader survey of more diverse cultivars and wild accessions may be necessary to find greater variability to this intrinsically elusive phenotype.

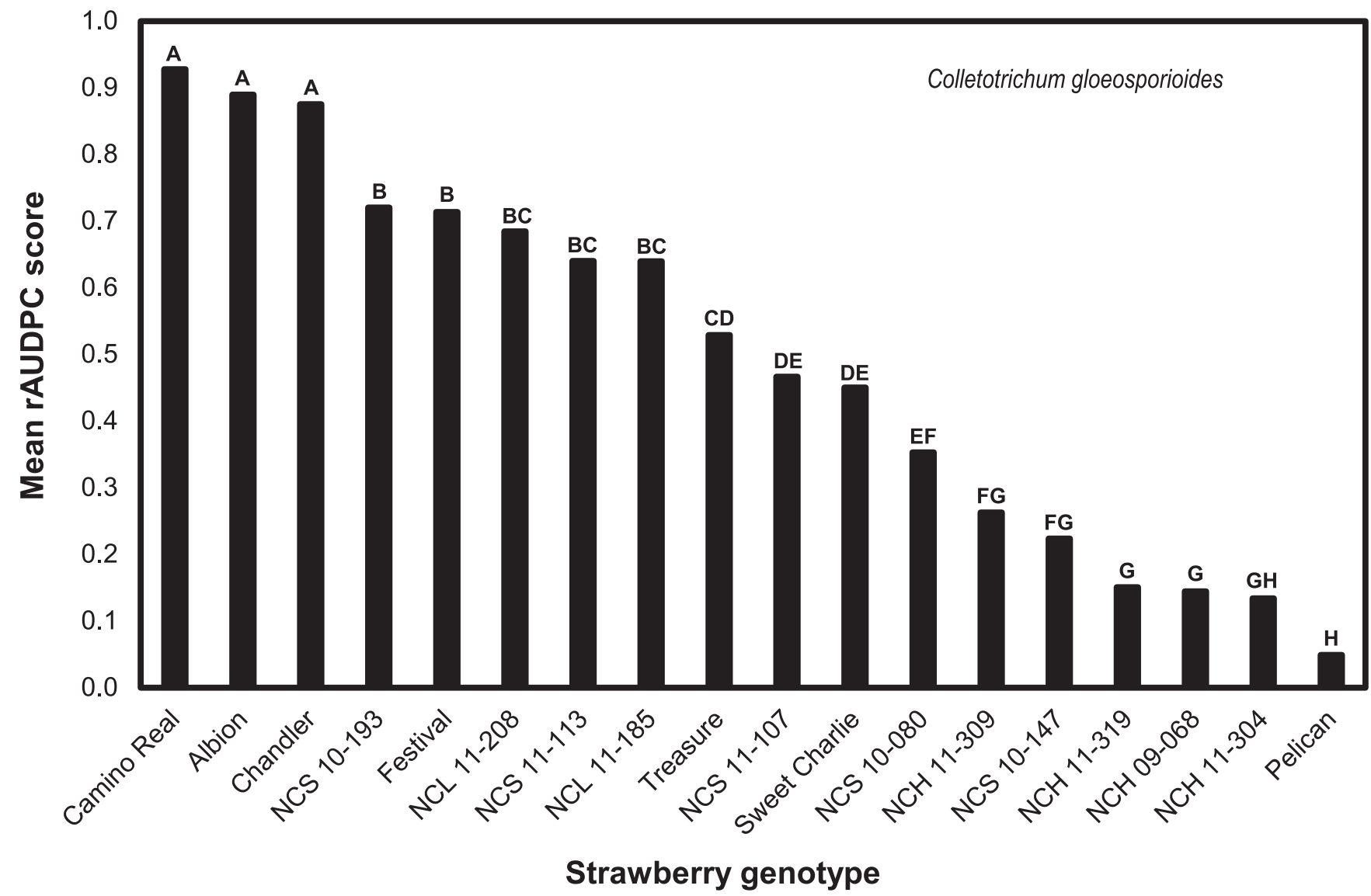

Fig. 4. Mean relative area under the disease progress curve (rAUDPC) values for 18 genotypes inoculated with Colletotrichum gloeosporioides and scores for anthracnose crown rot wilt severity. The letter grouping appears above each genotype. Genotypes with the same letter are not significantly different $(P \leq 0.05)$. 
It is also possible that, through an artificial inoculation using high inoculum density, minor resistance mechanisms may have been overwhelmed. This inoculation protocol was designed to mimic the splash dispersal of Colletotrichum conidia in the strawberry nursery but is not a perfect reproduction of the dynamics of that system. This inoculation method and experiment were designed to detect and differentiate resistance mechanisms within the leaf tissue itself. They would not allow us to detect other dynamics of the nursery system, such as the impact of plant morphology on the ability of inoculum to reach and infect leaf tissue. HBI is not a substitute for visual symptoms. HBIs establish asymptomatically and are only visualized through methods, such as the paraquat procedure, detailed in the paper. Commercially, the only indication of infected nursery stock is the appearance of fruit lesions or plant collapse in the fruiting field.

Estimates of PSLA served primarily as a rating parameter for characterizing rate-reducing resistance to $\mathrm{HBI}$ on foliar tissue, whereas estimates of rAUDPC differentiated genotypes based on resistance of the crown tissue. Strawberry cultivars and lines differed in susceptibility and levels of rate-reducing resistance to HBIs owing to both Colletotrichum species and differed in crown rot resistance when challenged with $C$. gloeosporioides. These findings open opportunities for additional genetic studies of resistance to both Colletotrichum species and to deploy anthracnose resistance in strawberry breeding programs in NC and the southeastern United States.

Both C. acutatum and C. gloeosporioides are hemibiotrophic pathogens that use a two-phase infection strategy: an asymptomatic biotrophic phase followed by a necrotrophic phase in which tissue damage is incurred (Arroyo et al. 2005; Gan et al. 2013; Muench et al. 2008; Peres et al. 2005; Perfect et al. 1999). Quiescence contributes to the overall success of an HBI strategy and is defined as an asymptomatic period between initial host infection and the activation of necrotrophic behavior and symptom expression (Gan et al. 2013; Leandro et al. 2001; Prusky et al. 2013). Understanding the variation in pathogenicity of local pathogen populations (MacKenzie et al. 2007) and understanding the infection cycle of Colletotrichum species (Arroyo et al. 2005; Freeman and Katan 1997) are relevant aspects to assess disease resistance in strawberry. In this study, a rapid increase in PSLA of many genotypes suggests the initiation of quiescent HBI between 0 and 6 DAI. The genotype most rapidly colonized by $C$. gloeosporioides was Festival, and the genotype most rapidly colonized by $C$. acutatum was Treasure: two commercial lines used in the southern United States and known to have a high level of field susceptibility to Colletotrichum species (Gupton and Smith 1991; Osorio et al. 2014; Poling 2008).

Smith and Black (1987) suggested that apparent field-level resistance may not be representative of true genetic resistance owing to high genotype by environment interactions. Thus, greenhouses offer many advantages to disease resistance studies when there is a critical need to minimize genotype by environment effects or meet certain parameters for disease establishment. Previous studies of resistance to Colletotrichum species have utilized greenhouses or other controlled environments to increase disease pressure and reduce environmental variability (Lewers et al. 2007; Rahman et al. 2013; Smith and Black 1987). Although many genotypes were significantly different in HBI severity, the most resistant genotype tested was NCS 10-147. Interestingly, NCS $10-147$ is the progeny of Treasure $(\mathrm{F}) \times$ Chandler (M), which were among two of the most susceptible genotypes screened in this study. The second most resistant genotype was NCS 10-080, and this genotype was also reported to be most resistant to foliar infections of $C$. acutatum in a previous study (Rahman et al.

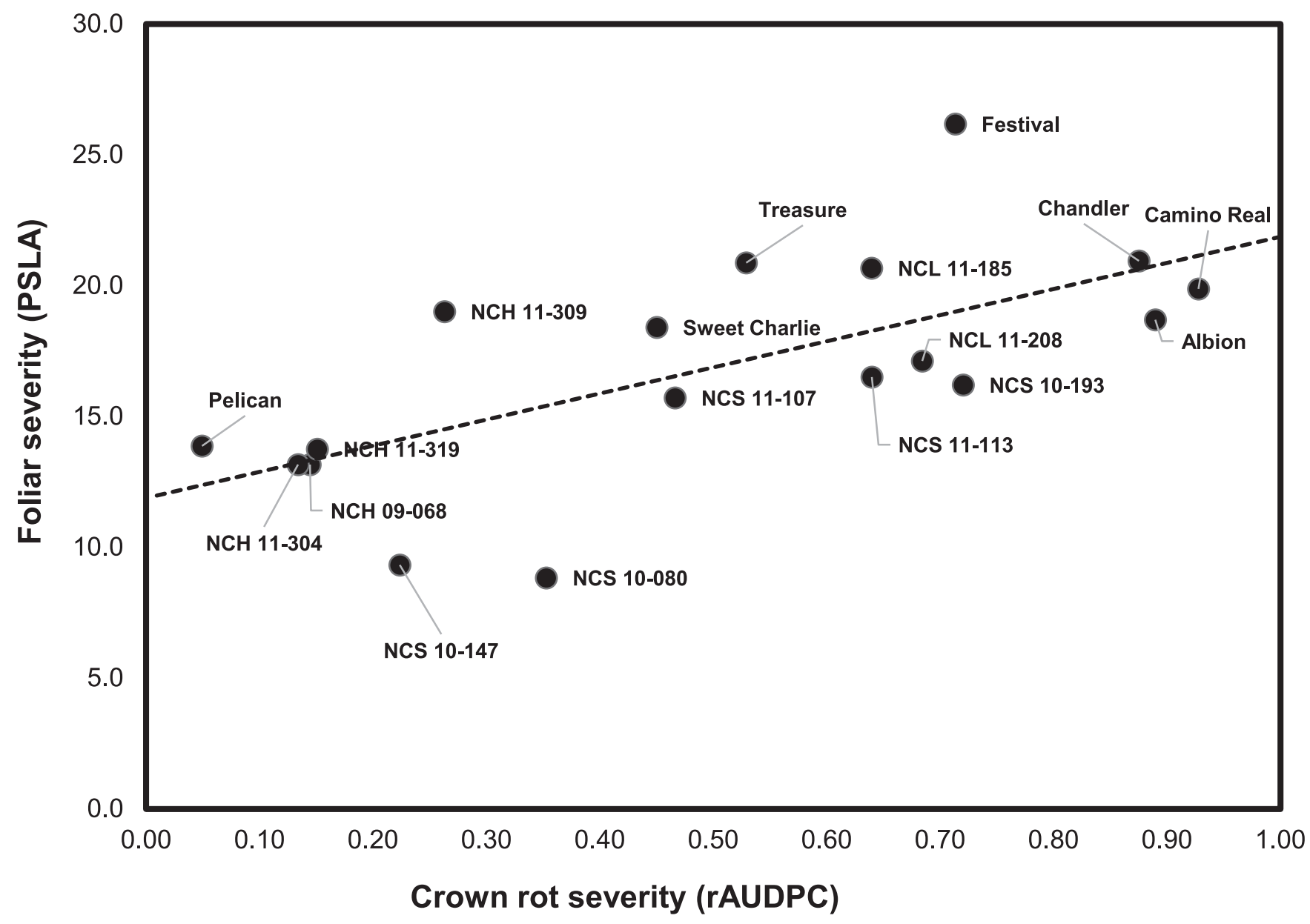

Fig. 5. Correlation between the average severity of leaf and crown tissue infection of 18 strawberry genotypes infected by Colletotrichum gloeosporioides. Leaf severity is given as percentage of sporulating leaf area (PSLA), and crown severity is given as the relative area under the disease progress curve (rAUDPC) value. 
2013). NCS 10-080 is the open-pollenated progeny of NC C02-63 (pedigree: NCR 97-53 [Pelican $\times$ Chandler] $\times$ Bish), the most resistant cultivar in a previous study of $C$. acutatum $\mathrm{HBI}$ and the line that had the highest level of field resistance to AFR (Rahman et al. 2013). Although evidence of the genetics of resistance to HBIs in strawberry leaf tissue is unclear, the low field incidence of AFR owing to $C$. acutatum (Rahman et al. 2013) and low AUDPC scores for PSLA detected in this study for two distantly related Colletotrichum species complexes (Cannon et al. 2012) warrant additional investigation.

Although there were no significant differences in PSLA values for 15 of 18 genotypes, several lines responded differentially to the two species. NCS $11-107$ had a $7.3 \%$ foliar severity difference between two Colletotrichum species, with C. acutatum being more severe than C. gloeosporioides in this genotype. The largest difference was found for Treasure, which had $11.9 \%$ greater severity for C. acutatum than C. gloeosporioides. This observed difference between Colletotrichum foliar infection in Treasure is analogous to established knowledge of Treasure's greater susceptibility to AFR than to ACR. MacKenzie et al. (2006) reported that a major resistance gene was associated with resistance to ACR in Treasure. We hypothesize that HBI resistance to both Colletotrichum species may not be controlled by the same genes or that only some of the genes involved in HBI resistance are common to both $C$. acutatum and C. gloeosporioides.

The HBI resistance may function as a rate-reducing resistance. Rate-reducing resistance is an active response by the host that slows the rate of epidemic development by restricting fungal colonization of the plant tissue (Parlevliet 1979; Tooley and Grau 1982, 1984). Decreased leaf colonization and an apparent decrease in total spore loads should decrease the overall rate of an epidemic in commercial strawberry nurseries and fruiting fields. Final incidence of AFR in harvested berries was negatively correlated with resistance to HBI and further decreased if selections also had fruit rot resistance, but the two traits were not linked in all lines evaluated (Rahman et al. 2013). Likewise, the rate of plant death owing to ACR could be correlated with quiescent infection levels or HBI incidence in mother and runner plants in the nursery. However, the level of resistance to the hemibiotrophic phase in leaves and the necrotrophic phase in crowns was weakly correlated in this study. Two cultivars Treasure and Sweet Charlie were moderately resistant to ACR, and these results are consistent with previous studies (Chandler et al. 1997; MacKenzie et al. 2007). Pelican exhibited a relatively high level of resistance to ACR, and it also was the most resistant cultivar reported in the previous study (Smith et al. 1998). However, Treasure and Sweet Charlie had relatively high levels of HBI, and Pelican was moderate. These data suggest that the two traits should be combined into strawberry cultivars to reduce inoculum load and direct ACR infections. We expect that correlation between the crown and foliar resistance phenotypes is likely genotype dependent and that stronger or weaker correlations may exist in different subsets of the strawberry germplasm. Similar studies on the inheritance of resistance in potato foliage and tubers found that resistance was controlled by major and minor genes and that correlation of resistance between tissues depended on the $R$ genes (and genotypes) in each population (Kirk et al. 2001; Liu and Halterman 2009; Park et al. 2005). Alternatively, it is possible that resistance to Colletotrichum species is controlled by several biochemical mechanisms effective during different stages of pathogenesis and in different host tissues.

In summary, results of this study provided proof of concept that methods used by Rahman et al. (2013) to evaluate resistance to HBI caused by $C$. acutatum can also be applied to assess resistance to $C$. gloeosporioides. It is likely that resistance to AFR caused by C. acutatum and ACR caused by $C$. gloeosporioides is controlled by different genes (Jacobs et al. 2019; Rahman et al. 2013). However, resistance to HBI in leaf tissue seems to operate at least partially under a different mode of inheritance. During the initial colonization process, both Colletotrichum species are capable of proliferating to epidemic proportions in the field or nursery. We hypothesize that C. acutatum and C. gloeosporioides enter a hemibiotrophic phase in which HBI resistance may be effective against both species during this intimate period of host-pathogen interaction (Jacobs 2015).
These results confirm anthracnose resistance in several strawberry cultivars and NC State University breeding lines (Jacobs et al. 2019) and highlight the importance of separate evaluation of plant tissues that may be under the control of different resistance mechanisms (Gupton and Smith 1991; Osorio et al. 2014). The use of visual assessment and the further development of image analyses have the potential to increase the accuracy and sensitivity of assessments of HBI and ACR in strawberry while reducing bias in the evaluations. This will be particularly important in strawberry breeding programs, because resistance to both $C$. acutatum and $C$. gloeosporioides is recognized as multigenic (Ballington et al. 2002; Jacobs et al. 2019; Osorio et al. 2014), requiring extreme sensitivity of disease assessment. To this end, our strawberry breeding program requires biological assays that allow us to discriminate minor differences between plants within a segregating population. Utilizing the methods developed in this study, we have further developed genetic mapping populations from the selected resistant lines to identify and map resistance genes or quantitative trait loci with molecular markers and to develop durably resistant cultivar(s) to both $C$. acutatum and $C$. gloeosporioides through marker-assisted selection. Additional work should be carried out to determine how resistance is inherited in these tissues (e.g., leaf versus crown and crown versus fruit), which may provide insight into mechanisms controlling resistance in diverse tissue types. Future research is necessary to determine the rate of inoculum increase in commercial fields and its contribution to crown rot and fruit rot epidemics in the production fields.

\section{Acknowledgments}

We thank Jason Osborne for helping in statistical analysis and The Plants for Human Health Institute (Kannapolis, NC) for providing greenhouse and laboratory facilities.

\section{Literature Cited}

Abd-El-Haliem, A. 2012. An unbiased method for the quantitation of disease phenotypes using a custom-built macro plugin for the program Image J. Methods Mol. Biol. 835:635-644.

Arroyo, F. T., Moreno, J., García-Herdugo, G., and de los Santos, B. 2005 Ultrastructure of the early stages of Colletotrichum acutatum infection of strawberry tissues. Can. J. Bot. 83:491-500.

Ballington, J. R., Shuman, J. L., Hokanson, S. C., Smith, B. J., and Giménez, G. 2002. Breeding strawberries (Fragaria $\mathrm{x}$ ananassa) for resistance to anthracnose caused by Colletotrichum acutatum. Acta Hortic. 567:89-92.

Bock, C. H., Poole, G. H., Parker, P. E., and Gottwald, T. R. 2010. Plant disease severity estimated visually, by digital photography and image analysis, and by hyperspectral imaging. Crit. Rev. Plant Sci. 29:59-107.

Baroncelli, R., Zapparata, A., Sarrocco, S., Sukno, S. A., Lane, C. R., Thon, M. R., Vannacci, G., Holub, E., and Sreenivasaprasad, S. 2015. Molecular diversity of anthracnose pathogen populations associated with UK strawberry production suggests multiple introductions of three different Colletotrichum species. PLoS ONE 10:e0129140.

Campbell, C. L., and Madden, L. V. 1990. Introduction to Plant Disease Epidemiology. Wiley, New York, NY.

Cannon, P. F., Damm, U., Johnston, P. R., and Weir, B. S. 2012 Colletotrichum - current status and future directions. Stud. Mycol. 73:181-213.

Cerkauskas, R. F., and Sinclair, J. B. 1982. Effect of par aquat on soybean pathogens and tissues. Trans. Br. Mycol. Soc. 78:495-502.

Chandler, C. K., Albregts, E. E., Howard, C. M., and Brecht, J. K. 1997. 'Sweet Charlie' strawberry. HortSci. 32:1132-1133.

Damm, U., Cannon, P. F., Woudenberg, J. H. C., and Crous, P. W. 2012. The Colletotrichum acutatum species complex. Stud. Mycol. 73:37-113.

Delp, B. R., and Milholland, R. D. 1980. Factors affecting disease development of strawberries infected with Colletotrichum fragariae. Phytopathology 70 : 566-567.

De Silva, D. D., Crous, P. W., Ades, P. K., Hyde, K. D., and Taylor, P. W. J. 2017. Life styles of Colletotrichum species and implications for plant biosecurity. Fungal Biol. Rev. 31:155-168.

Freeman, S., Horowitz, S., and Sharon, A. 2001. Pathogenic and nonpathogenic lifestyles in Colletotrichum acutatum from strawberry and other plants. Phytopathology 91:986-992.

Freeman, S., and Katan, T. 1997. Identification of Colletotrichum species responsible for anthracnose and root necrosis of strawberry in Israel. Phytopathology 87:516-521.

Fry, W. E. 1978. Quantification of general resistance of potato cultivars and fungicide effects for integrated control of potato late blight. Phytopathology 68:1650-1655 
Gan, P., Ikeda, K., Irieda, H., Narusaka, M., O'Connell, R. J., Narusaka, Y., Takano, Y., Kubo, Y., and Shirasu, K. 2013. Comparative genomic and transcriptomic analyses reveal the hemibiotrophic stage shift of Colletotrichum fungi. New Phytol. 197:1236-1249.

Garrido, C., Carbu, M., Fernandez-Acero, F. J., Boonham, N., Colyer, A., Cantoral, J. M., and Budge, G. 2009. Development of protocols for detection of Colletotrichum acutatum and monitoring of strawberry anthracnose using real-time PCR. Plant Pathol. 58:43-51.

Gunnell, P. S., and Gubler, W. D. 1992. Taxonomy and morphology of Colletotrichum species pathogenic to strawberry. Mycologia 84:157-165.

Gupton, C. L., and Smith, B. J. 1991. Inheritance of resistance to Colletotrichum species in strawberry. J. Am. Soc. Hortic. Sci. 116:724-727.

Howard, C. M., Maas, J. L., Chandler, C. K., and Albregts, E. E. 1992. Anthracnose of strawberry caused by the Colletotrichum complex in Florida. Plant Dis. 76:976-981

Jacobs, R., Adhikari, T. B., Pattison, J., Yencho, G. C., Fernandez, G. E., and Louws, F. J. 2019. Inheritance of resistance to Colletotrichum gloeosporioides and $C$. acutatum in strawberry. Phytopathology 109:428-435.

Jacobs, R. L., III. 2015. Inheritance of rate-limiting foliar resistance to anthracnose crown rot and fruit rot in cultivated strawberry. $\mathrm{PhD}$ dissertation. North Carolina State University, Raleigh, NC

Kirk, W. W., Felcher, K. J., Douches, D. S., Niemira, B. A., and Hammerschmidt, R. 2001. Susceptibility of potato (Solanum tuberosum L.) foliage and tubers to the US8 genotype of Phytophthora infestans. Am. J. Potato Res. 78:319-322.

Kumar, S., Stecher, G., and Tamura, K. 2016. MEGA7: Molecular evolutionary genetics analysis version 7.0 for bigger datasets. Mol. Biol. Evol. 33: 1870-1874.

Leandro, L. F. S., Gleason, M. L., Nutter, F. W., Jr., Wegulo, S. N., and Dixon, P. M. 2001. Germination and sporulation of Colletotrichum acutatum on symptomless strawberry leaves. Phytopathology 91:659-664.

Leandro, L. F. S., Gleason, M. L., Nutter, F. W., Jr., Wegulo, S. N., and Dixon, P. M. 2003. Influence of temperature and wetness duration on conidia and appressoria of Colletotrichum acutatum on symptomless strawberry leaves. Phytopathology 93:513-520.

Legard, D. E. 2000. Colletotrichum diseases of strawberry in Florida. Pages 292299 in: Colletotrichum: host specificity, pathology, and host-pathogen interaction. D. Prusky, S. Freeman, and M. Dickman, eds. APS Press, St. Paul, MN.

Lewers, K. S., Turechek, W. W., Hokanson, S. C., Maas, J. L., Hancock, J. F., Serçe, S., and Smith, B. J. 2007. Evaluation of elite native strawberry germplasm for resistance to anthracnose crown rot disease caused by Colletotrichum species. J. Am. Soc. Hortic. Sci. 132:842-849.

Liu, Z., and Halterman, D. 2009. Different genetic mechanisms control foliar and tuber resistance to Phytophthora infestans in wild potato Solanum verrucosum. Am. J. Potato Res. 86:476-480.

Louws, F. J., and Rahman, M. 2012. Strawberry disease management. Pages 30-31 in: Southeast Regional Strawberry Integrated Management Guide. F. J. Louws, ed. NCSU CNR publications, Raleigh, NC.

MacKenzie, S. J., Legard, D. E., Timmer, L. W., Chandler, C. K., and Peres, N. A. 2006. Resistance of strawberry cultivars to crown rot caused by Colletotrichum gloeosporioides isolates from Florida is nonspecific. Plant Dis. 90:1091-1097.

MacKenzie, S. J., Mertely, J. C., and Peres, N. A. 2009. Curative and protectant activity of fungicides for control of crown rot of strawberry caused by Colletotrichum gloeosporioides. Plant Dis. 93:815-820.

MacKenzie, S. J., Seijo, T. E., Legard, D. E., Timmer, L. W., and Peres, N. A. 2007. Selection for pathogenicity to strawberry in populations of Colletotrichum gloeosporioides from native plants. Phytopathology 97:1130-1140.

Madden, L. V., Hughes, G., and van den Bosch, F. 2007. The Study of Plant Disease Epidemics. APS Press, St. Paul, MN

Muench, S., Lingner, U., Floss, D. S., Ludwig, N., Sauer, N., and Deising, H. B. 2008. The hemibiotrophic lifestyle of Colletotrichum species. J. Plant Physiol. 165:41-51

Murray, M. G., and Thompson, W. F. 1980. Rapid isolation of high molecular weight plant DNA. Nucleic Acids Res. 8:4321-4325.
Nutter, F. W., Jr., Esker, P. D., and Coelho Netto, R. A. 2006. Disease assessment concepts and the advancements made in improving the accuracy and precision of plant disease data. Eur. J. Plant Pathol. 115:95-103.

Oliver, R. O., and Ipcho, S. V. S. 2004. Arabidopsis pathology breathes new life into the necrotrophs vs. biotrophs classification of fungal pathogens. Mol. Plant Pathol. 5:347-352.

Osorio, L. F., Pattison, J. A., Peres, N. A., and Whitaker, V. M. 2014. Genetic variation and gains in resistance of strawberry to Colletotrichum gloeosporioides. Phytopathology 104:67-74.

Park, T. H., Vleeshouwers, V. G. A. A., Kim, J. B., Hutten, R. C. B., and Visser, R. G. F. 2005. Dissection of foliage and tuber late blight resistance in mapping populations of potato. Euphytica 143:75-83

Parlevliet, J. E. 1979. Components of resistance that reduce the rate of epidemic development. Annu. Rev. Phytopathol. 17:203-222.

Peres, N. A., Timmer, L. W., Adaskaveg, J. E., and Correll, J. C. 2005. Lifestyles of Colletotrichum acutatum. Plant Dis. 89:784-796.

Perfect, S. E., Hughes, H. B., O'Connell, R. J., and Green, J. R. 1999. Colletotrichum - A model genus for studies on pathology and fungal-plant interactions. Fungal Genet. Biol. 27:186-198.

Poling, E. B. 1993. Strawberry plasticulture in North Carolina: Preplant, planting, and postplant considerations for growing 'Chandler' strawberry on black plastic mulch. HortTech. 3:383-393.

Poling, E. B. 2008. Anthracnose on strawberry: Its etiology, epidemiology, and pathology, together with management strategies for strawberry nurseries: Introduction to the workshop. HortSci. 43:59-65.

Prusky, D., Alkan, N., Mengiste, T., and Fluhr, R. 2013. Quiescent and necrotrophic lifestyle choice during postharvest disease development. Annu. Rev. Phytopathol. 51:155-176.

Rahman, M., Ballington, J., and Louws, F. 2013. Role of foliar hemibiotrophic and fruit resistance in anthracnose-resistant strawberry genotypes for annual hill plasticulture systems. Ann. Appl. Biol. 163:102-113.

Rahman, M., Ojiambo, P., and Louws, F. 2015. Initial inoculum and spatial dispersal of Colletotrichum gloeosporioides, the causal agent of strawberry anthracnose crown rot. Plant Dis. 99:80-86.

Shaner, G., and Finney, R. E. 1977. Effect of nitrogen-fertilization on expression of slow-mildewing resistance in knox wheat. Phytopathology 67:1051-1056.

Smith, B. J. 2008. Epidemiology and pathology of strawberry anthracnose: A North American perspective. HortSc. 43:69-73.

Smith, B. J., and Black, L. L. 1987. Resistance of strawberry plants to Colletotrichum fragariae affected by environmental conditions. Plant Dis. 71:834-837.

Smith, B. J., and Black, L. L. 1990. Morphological, cultural, and pathogenic variation among Colletotrichum species isolated from strawberry. Plant Dis. 74:69-76.

Smith, B. J., Gupton, C. L., Galletta, G. J., Maas, J. L., Enns, J. M., Ballington, J. R., Jr., Constantin, R. J., DiVittorio, T. J., and Himelrick, D. 1998. 'Pelican' strawberry. HortSci. 33:1082-1084

Smith, B. J., and Spiers, J. M. 1982. Evaluating techniques for screening strawberry seedlings for resistance to Colletotrichum fragariae. Plant Dis. 66: 559-561.

Tooley, P. W., and Grau, C. R. 1982. Identification and quantitative characterization of rate-reducing resistance to Phytophthora megasperma $\mathrm{f}$ sp. glycinea in soybean seedlings. Phytopathology 72:727-733.

Tooley, P. W., and Grau, C. R. 1984. Field characterization of rate-reducing resistance to Phytophthora megasperma f. sp. glycinea in soybean. Phytopathology 74:1201-1208.

Weir, B. S., Johnston, P. R., and Damm, U. 2012. The Colletotrichum gloeosporioides species complex. Stud. Mycol. 73:115-180.

Wijekoon, C., Goodwin, P. H., and Hsiang, T. 2008. Quantifying fungal infection of plant leaves by digital image analysis using Scion Image software. J. Microbiol. Methods 74:94-101.

Xie, L., Zhang, J., Wan, Y., and Hu, D. 2010. Identification of Colletotrichum spp isolated from strawberry in Zhejiang Province and Shanghai City, China. J. Zhejiang Univ. 11:61-70.

Zadoks, J. C., and Schein, R. D. 1979. Epidemiology and Plant Disease Management. Oxford University Press, New York, NY. 